\title{
Juxtaposition of Polyethersulfone Composite Membranes: Performance and Antifouling Capability
}

\author{
Nur Dina Zaulkiflee, ${ }^{1}$ Abdul Latif Ahmad, ${ }^{1 *}$ Liau Xin Jie ${ }^{1}$ and Adhi Kusumastuti ${ }^{2}$ \\ ${ }^{1}$ School of Chemical Engineering, Universiti Sains Malaysia, Engineering Campus, \\ 14300, Nibong Tebal, Pulau Pinang, Malaysia \\ ${ }^{2}$ Faculty of Engineering, Universitas Negeri Semarang (UNNES), \\ Kampus UNNES Sekaran, Semarang 50229, Indonesia \\ *Corresponding author: chlatif@usm.my
}

Published online: 25 December 2019

To cite this article: Zaulkiflee, N. D. et al. (2019). Juxtaposition of polyethersulfone composite membranes: Performance and antifouling capability. J. Phys. Sci., 30(Supp. 2), 13-22, https://doi.org/10.21315/jps2019.30.s2.2

To link to this article: https://doi.org/10.21315/jps2019.30.s2.2

\begin{abstract}
Wastewater treatment has become a pressing challenge due to the generation of its large amount by daily life usage and industrial processes. To this regard, membrane technology has been a household name for such treatment. In this work, three inorganic additives, namely silicon dioxide $\left(\mathrm{SiO}_{2}\right)$, titanium oxide $\left(\mathrm{TiO}_{2}\right)$ and zinc oxide $(\mathrm{ZnO})$ were selected and blended with polyethersulfone (PES) to prepare a PES-composite membrane using the phase inversion technique. The effects of various inorganic additives on performance of as-membranes for oil water emulsion separation were evaluated via the cross-flow ultrafiltration process. Membranes embedded with TiO2 nanoparticles (NPS) presents the highest permeate flux and pure water flux of $7.95 \mathrm{~kg} / \mathrm{m} 2 . \mathrm{h}$ and $21.68 \mathrm{~kg} / \mathrm{m} 2 . \mathrm{h}$, respectively. Furthermore, it also presents the lowest fouling phenomenon among the membranes with relative flux reduction and flux recovery ratio of $63.33 \%$ and $48.57 \%$, respectively.
\end{abstract}

Keywords: Inorganic additives, silicon dioxide, titanium oxide, zinc oxide, oil-in-water separation

\section{INTRODUCTION}

Membranes used in wastewater treatments have received an increased attention due to the process efficiency at removing turbidity, particles and microorganisms. ${ }^{1}$ The use of membrane has increased exponentially making it economically competitive with traditional water treatment methods. ${ }^{2}$ Various membrane materials such as 
cellulose acetate (CA), polysulfone (Psf), polyethersulfone (PES), polyacrylonitrile (PAN), polyvinylidene fluoride (PVDF) and polyimide (PI) have been used in both water and wastewater treatments. PES is one of the most used polymeric materials in membrane applications. It is transparent, amorphous and a high- $\mathrm{Tg}\left(225^{\circ} \mathrm{C}\right)$ polymer with high chemical resistances, mechanical and thermal properties. ${ }^{3}$ These properties have encouraged its wide use in preparing membranes with varieties of pore sizes and surfaces. Compared with multiple membrane materials, one major usage of PES membranes is their high hydrophobicity, causing severe fouling when utilised for oily wastewater treatment. ${ }^{4}$ Fouling is caused by the adsorption of solute on the membrane surface and pores, which results in slow filtration rate, higher energy demand and unpredictable performance during separation. ${ }^{5,6}$ This causes limited industrial utilisation of the membrane.

Nevertheless, several efforts have been proposed by fellow researchers in order to overcome this fouling problem. ${ }^{2,3,7,8}$ Thus, to reduce this hydrophobicity, various methods have been introduced such as blending and surface modification (via coating and grafting). Various additives such as the use of organic and inorganic materials plays a significant importance in these techniques. Many researchers have blended hydrophilic inorganic materials with polymer material to form composite membrane in order to obtain higher performance membrane. Change in composite membrane characteristics such as hydrophilicity, thermal, mechanical and antifouling is expected compared to neat membrane. Therefore, the incorporation of inorganic additives have found prominent space due their numerous advantages such as simplicity in the preparation technology and operating process. ${ }^{9}$ The addition of inorganic nanoparticles have been reported to improve pore formation, surface hydrophilicity and enhance antifouling properties. ${ }^{10}$ Basically, the use of inorganic additives can be carried out by introducing them in the dope solution (often known as blending) or coating the nanoparticles (NPs) on the surface of asmembrane via surface attachments. ${ }^{11-13}$

The former approach has proven to be versatile in recent times. The use of inorganic additives has been selected from a wide variety including $\mathrm{TiO}_{2}, \mathrm{SiO}_{2}, \mathrm{ZnO}, \mathrm{CNTs}$, $\mathrm{Al}_{2} \mathrm{O}_{3}$ and $\mathrm{ZrO}_{2}$, etc. In the preparation of mixed matrix membranes (MMM)'s for oily wastewater treatment, $\mathrm{TiO}_{2}, \mathrm{ZnO}$ and $\mathrm{SiO}_{2} \mathrm{NPs}$ are widely used incorporated with $\mathrm{TiO}_{2}$ NPs in PES matrix to prepare PES nanofiltration (NF) membranes where they observed an improvement in the antifouling properties and water permeability. ${ }^{14}$ The prepared membrane with $4 \mathrm{wt} \% \mathrm{TiO}_{2}$ showed an increase in the flux recovery ratio (FRR) from $56 \%$ to $91 \%$. However, at a low content of $\mathrm{TiO}_{2}$ $(<4 \mathrm{wt} \%)$, there was significant reduction of biofouling effects which was a result of less aggregation observed under SEM. Meanwhile, high content of $\mathrm{TiO}_{2}$ causes the performance of membrane to decrease. Ahmad et al. observed some significant 
improvement in antifouling properties as well as membrane properties upon the incorporation of $\mathrm{ZnO}$ into the PES matrix. ${ }^{15}$ Otitoju et al. incorporated $\mathrm{SiO}_{2}$ in the polymer matrix to prepare a $\mathrm{PES} / \mathrm{SiO}_{2}$ composite membrane. ${ }^{16}$ They observed an increase in oil rejection, pure water flux and permeate flux from $95.77 \%$ to $97.48 \%$, $87.347 \mathrm{l} \mathrm{m}^{-2} \mathrm{~h}^{-1}$ to $91.9491 \mathrm{~m}^{-2} \mathrm{~h}^{-1}$, and $60 \mathrm{l} \mathrm{m}^{-2} \mathrm{~h}^{-1}$ to $\sim 75 \mathrm{l} \mathrm{m}^{-2} \mathrm{~h}^{-1}$, respectively.

There is no doubt that embedding inorganic additives in the polymer matric improves membrane performance and antifouling ability as depicted in literature, yet, their difference remains controversial. Addition of nanoparticles to PES membrane was believed able to improve hydrophilicity and antifouling properties of the membranes as compared to pure PES membrane. To give their differences in terms of performance and their antifouling effects for oily wastewater treatment, that this current work is important. Therefore, this work aims to gain useful insight into the influence of varying inorganic additives such as $\mathrm{SiO}_{2}, \mathrm{ZnO}$ and $\mathrm{TiO}_{2}$ in the PES matrix on the membrane performance. The membranes were prepared via phase inversion technique. The membranes were subsequently evaluated for oilin-water emulsion.

\section{EXPERIMENTAL}

\subsection{Materials}

PES (Mw of $\left.58 \mathrm{~kg} \mathrm{~mol}^{-1}\right)$ was obtained from BASF. Titanium dioxide $\left(\mathrm{TiO}_{2}\right.$, $99 \%$ ), polyvinylpyrrolidone (MWCO $10 \mathrm{kDa}$ ), and tween 80 were provided by Sigma Aldrich. Ethanol $\left(\mathrm{C}_{2} \mathrm{H}_{5} \mathrm{OH}\right)$ and N-methyl-2-pyrrolidone (NMP, 99.5\%) were provided by Merck, Malaysia. Zinc oxide (10-30 nm) and silicon dioxide (63-200 nm) was provided by United States Research Nanomaterials Inc. and Fluka, respectively. Crude oil was supplied by Petronas, Malaysia. Liquid nitrogen was provided by Wellgas, Malaysia. $\mathrm{PES}, \mathrm{TiO}_{2}, \mathrm{ZnO}, \mathrm{SiO}_{2}$ were dried at $75^{\circ} \mathrm{C}$ for $\sim 5 \mathrm{~h}$ prior to use.

\subsection{Membrane Preparation}

The flat sheet membranes were prepared via phase inversion methods. In brief, the $\mathrm{NPs}\left(\mathrm{ZnO}, \mathrm{TiO}_{2}\right.$ and $\left.\mathrm{SiO}_{2}\right)$ were added in NMP and stirred for $2 \mathrm{~h}$ at temperature of $55^{\circ} \mathrm{C}$ with speed of $300 \mathrm{rpm}$. Subsequently, PVP and PES were added to the mixture and stirred continuously for about $15 \mathrm{~h}$ until full dissolution. Table 1 shows the formulation for the fabrication of the membranes. The homogenous mixture was later transferred into ultrasonic bath for at least $4 \mathrm{~h}$ to obtain a bubble-free solution. The dope solution was casted on a glass plate using a casting blade of $20 \mu \mathrm{m}$. 
Thereafter, the as-membranes were immediately immersed into a coagulation bath (containing distilled water) for $24 \mathrm{~h}$ and the distilled water was changed every $4 \mathrm{~h}$ in order to completely remove all trapped solvents within the membranes. Finally, the membrane was dried in at room temperature prior to performance testing.

Table 1: Composition of prepared membranes

\begin{tabular}{lcccccc}
\hline Membranes & NMP (wt\%) & PVP (wt\%) & PES (wt\%) & $\mathrm{TiO}_{2}(\mathrm{wt} \%)$ & $\mathrm{SiO}_{2}(\mathrm{wt} \%)$ & $\mathrm{ZnO}(\mathrm{wt} \%)$ \\
\hline $\mathrm{P}$ & 80.25 & 2.5 & 17.25 & - & - & - \\
$\mathrm{Ti}$ & 79.5 & 2.5 & 17.25 & 0.75 & - & - \\
$\mathrm{Si}$ & 79.5 & 2.5 & 17.25 & - & 0.75 & - \\
$\mathrm{Zn}$ & 79.5 & 2.5 & 17.25 & - & - & 0.75 \\
\hline
\end{tabular}

\subsection{Membrane Performance}

\subsubsection{Synthetic oil in water emulsion preparation}

The preparation of synthetic crude oil-in-water emulsion was carried out by adding and dissolving $0.03 \mathrm{ml}$ Tween and $0.14 \mathrm{ml}$ crude oil in $999.83 \mathrm{ml}$ deionised water to make a $100 \mathrm{mg} \mathrm{l}^{-1}$ crude oil-in-water emulsion. Their dispersion was carried out using the blender (Khind BL-1515, $300 \mathrm{~W}$ ) for about $10 \mathrm{~min}$. In order to release trapped air bubbles, the solution was subsequently sonicated for $\sim 5 \mathrm{~min}$.

\subsubsection{Ultrafiltration testing}

The membrane performance was tested using the cross-flow filtration setup. The filtration performance testing was conducted using membrane with an effective filtration area, feed flow rate, transmembrane pressure and filtration time of $34 \mathrm{~cm}^{2}$, $400 \mathrm{ml} \mathrm{min}{ }^{-1}, 1.5 \mathrm{bar}$ and $2 \mathrm{~h}$, respectively. Prior to testing, membranes were compressed using distilled water at 2 bars for $30 \mathrm{~min}$. Membrane flux (permeate flux, initial pure water flux and pure water flux after backflushing) using the below equation:

$$
F=\frac{V}{(\Delta t * A)}
$$

where $V, A, F$ and $\Delta t$ are the permeate volume $(\mathrm{kg})$, membrane effective area $\left(\mathrm{m}^{2}\right)$, membrane flux $\left(\mathrm{kg} \mathrm{m}^{-2} \mathrm{~h}^{-1}\right)$ and filtration time (h), respectively.

After $2 \mathrm{~h}$ of water flux measurement, the feed was replaced with the crude oil solution and the permeate flux result was also obtained using Equation 1 whereas the oil rejection efficiency was obtained using Equation 2: 


$$
\mathrm{R}=\left(1-\frac{\mathrm{C}_{\mathrm{p}}}{\mathrm{C}_{\mathrm{o}}}\right) \times 100
$$

where $\mathrm{C}_{\mathrm{p}}, \mathrm{R}$, and $\mathrm{C}_{\mathrm{o}}$ refer to oil concentration in permeate, oil rejection percentage, and oil concentration in the feed, respectively. Oil concentration in the permeate and feed were measured at a wavelength of $225 \mathrm{~nm}$ using the UV-Vis spectrophotometer (Spectroquant Pharo 300, Merck).

At the end of the oil separation performance, the membranes were subsequently backflushed using distilled water for $30 \mathrm{~min}$ and feed flow rate of $1000 \mathrm{ml} \mathrm{min} \mathrm{m}^{-1}$. Thereafter, a new pure water flux $\left(\mathrm{F}_{1}\right)$ was obtained and calculated using Equation 1. Finally, the antifouling parameters including flux recovery ratio (FRR) as well as relative flux reduction (RFR) were calculated using the equations below:

$$
\begin{aligned}
& F R R=\frac{F_{2}}{F_{1}} \times 100 \\
& R F R=\frac{F_{1}-P F}{F_{1}} \times 100
\end{aligned}
$$

where $F_{2}, F_{1}$ and $P F$ are pure water flux after backflushing, initial pure water flux, and permeate flux (units in $\mathrm{kg} \mathrm{m}^{-2} \mathrm{~h}^{-1}$ ), respectively. Basically, high FRR and low RFR signify better anti-fouling properties.

\section{RESULTS AND DISCUSSIONS}

\subsection{Membrane Performance}

\subsubsection{Membrane ultrafiltration performance}

Figure 1 presents the initial pure water flux $\left(F_{1}\right)$ and permeate flux $(P F)$ for all prepared membranes $(\mathrm{P}, \mathrm{Ti}, \mathrm{Si}$ and $\mathrm{Zn})$. Based on the figure, membrane incorporated with $\mathrm{TiO}_{2}$ (Ti) presents the highest $P F$ and $F_{1}$ of $7.95 \mathrm{~kg} \mathrm{~m}^{-2} \mathrm{~h}^{-1}$ and $21.68 \mathrm{~kg} \mathrm{~m}^{-2} \mathrm{~h}^{-1}$, respectively. Pure water flux and permeate flux show a similar trend which increases in the order of $\mathrm{P}<\mathrm{Zn}<\mathrm{Si}<\mathrm{Ti}$. As observed, all composite membranes have $P F$ and $F_{1}$ which were higher than the pristine membrane $(\mathrm{P})$. Incorporation of inorganic additive was able to enhance the permeability of membrane. This also has been noted in several works in literatures. ${ }^{17-20}$ In these works, such phenomenon were attributed due to surface hydrophilicity and free volume on the surface of membrane which provides more site for the water adsorption. ${ }^{21}$ 


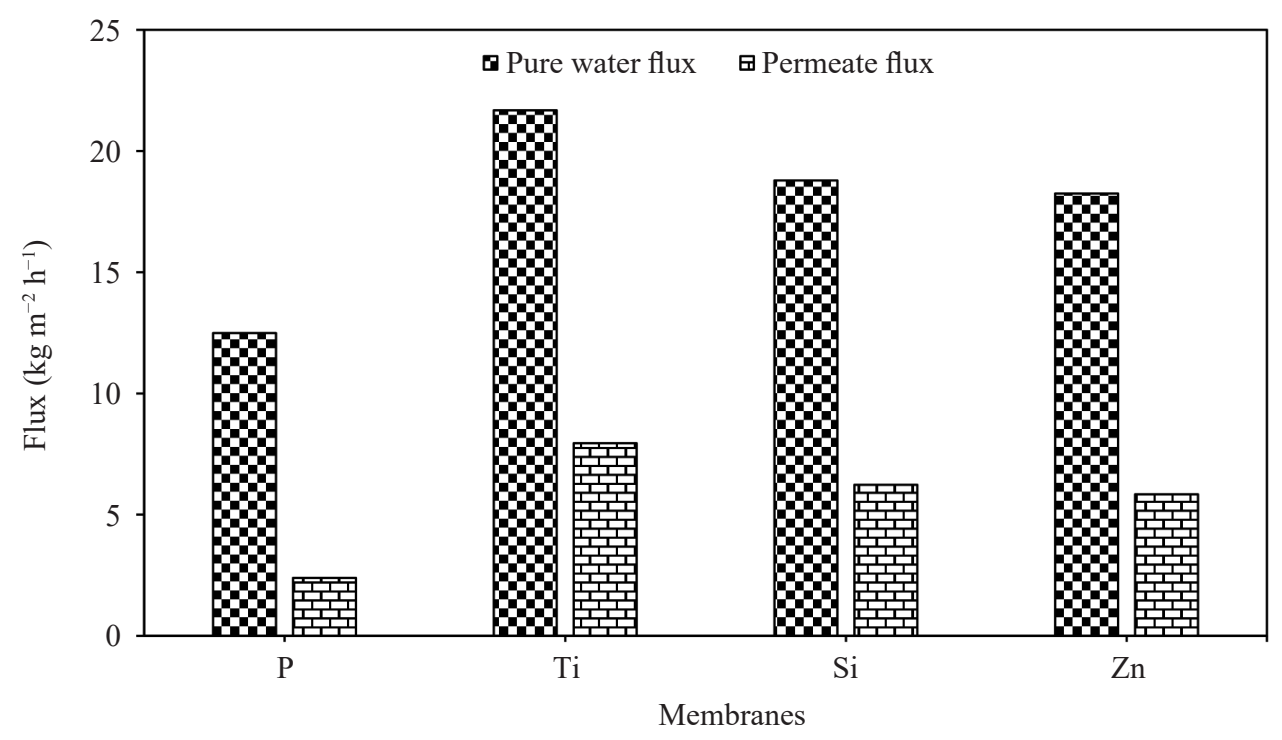

Figure 1: Pure water flux and permeate flux of membranes.

\subsubsection{Antifouling performance}

One of the major threats in membrane separation is membrane fouling which is caused by accumulation of oil layers on the membrane surface. Therefore, FRR and RFR were used as parameters to test the antifouling capability of the as-membranes and their results are presented in Figure 2. The higher the value of FRR, the lower the fouling is for the respective membrane. As observed, all composite membranes show better antifouling properties as compared to pristine membrane. The membrane incorporated with $\mathrm{TiO}_{2}$ (Ti) presents the lowest RFR with $48.57 \%$, respectively. This result also proved that the addition of inorganic additives has a great potential to improve the antifouling properties of membranes which is similar to other literatures. ${ }^{22}$ On the other hand, RFR values were opposite to FRR value. Low RFR value means less fouling occur. In this study, the lowest RFR was $63.33 \%$ belonging to $\mathrm{TiO}_{2}$ (Ti) while the highest RFR was $80.86 \%$ which was resulted by neat PES membrane (P). Obviously, inorganic nanoparticles play a role in reducing fouling.

\subsubsection{Rejection performance}

Figure 3 represents the separation efficiency for oily waste water for membranes $(\mathrm{P}, \mathrm{Ti}, \mathrm{Si}$ and $\mathrm{Zn})$. In comparison with the pristine membrane of $83.4 \%$, all composite membranes exhibit higher oil rejection in the range of $87.62 \%$ to $90.97 \%$. The highest oil rejection was achieved by membrane $\mathrm{Si}$, followed by $\mathrm{Zn}$ 
and $\mathrm{Ti}$, respectively. Despite having the highest water permeability among other composite membranes for membrane incorporated with $\mathrm{TiO}_{2}$, this membrane had the lowest oil rejection (higher than the pristine membrane). The reason might be due to the passage of some oil droplets with higher passage of water molecules. ${ }^{23}$

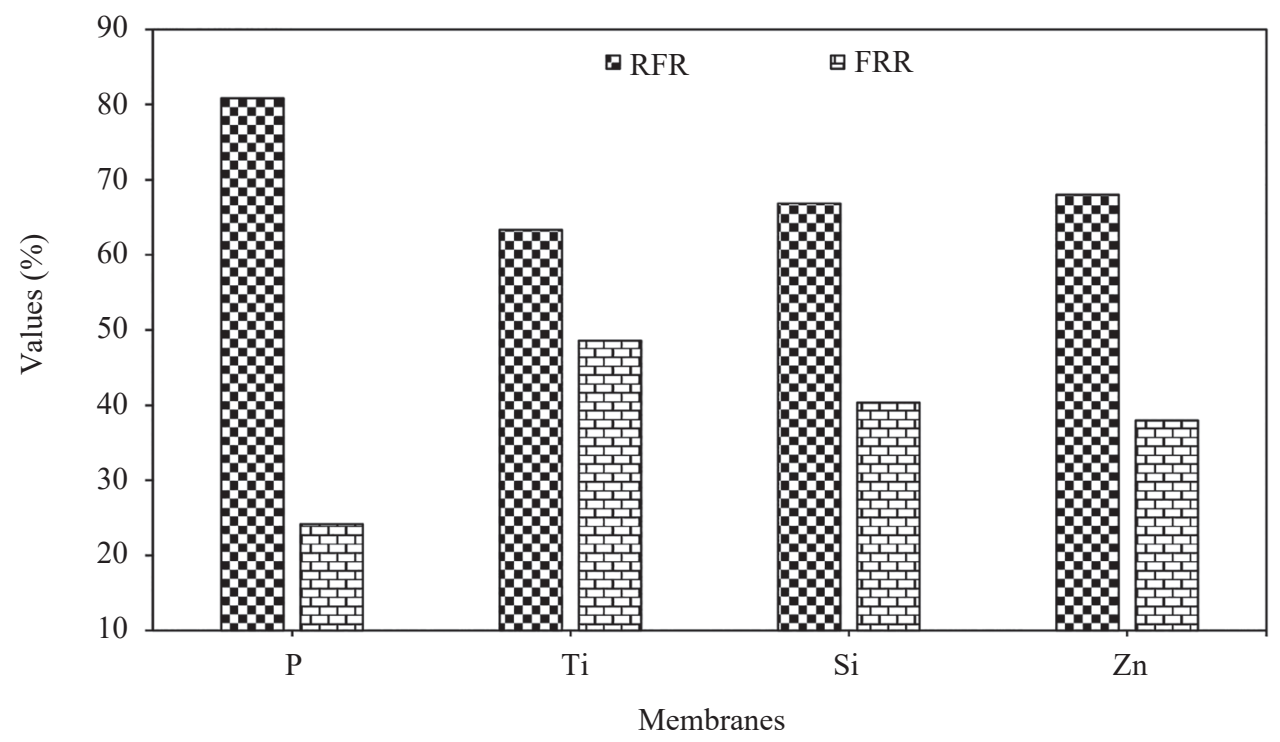

Figure 2: RFR and FRR of membranes.

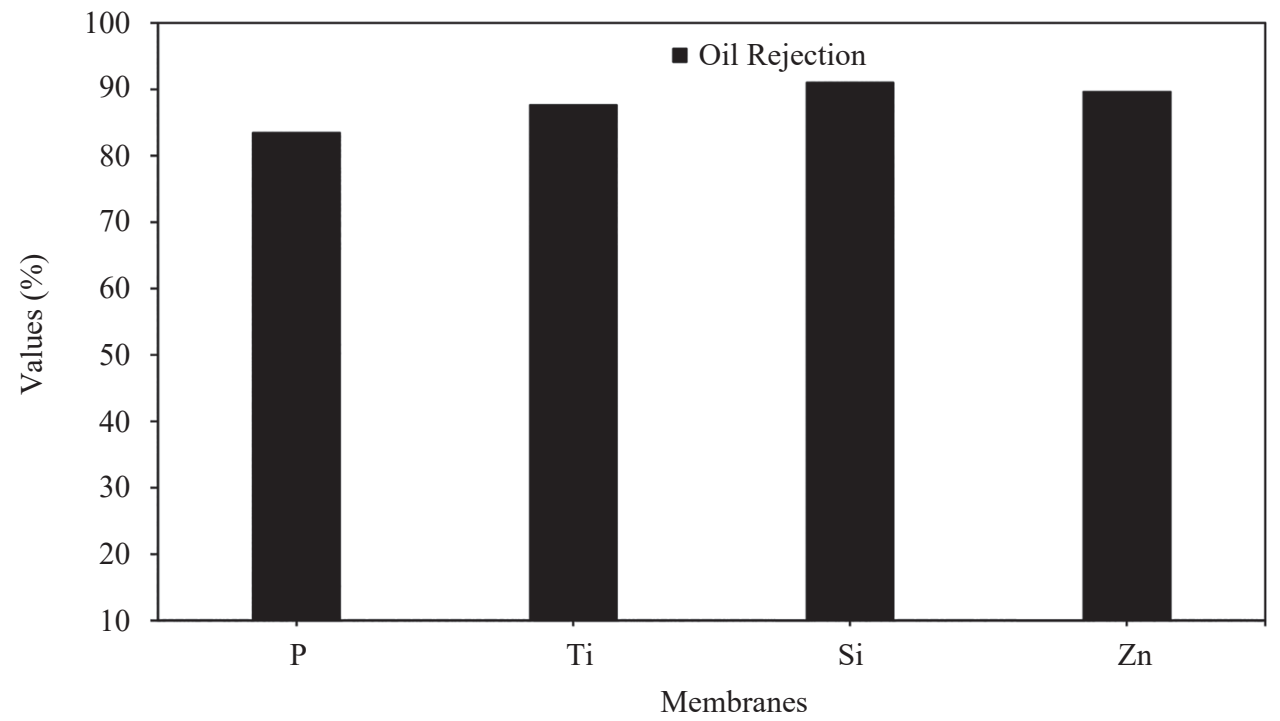

Figure 3: Oil rejection performance of membranes. 


\section{CONCLUSION}

In this work, various membranes were prepared by doping with three inorganic additives in the PES matrix via the phase inversion technique and their differences in performance (in terms of water permeability, oil separation efficiencies as well as their anti-fouling properties) were evaluated for crude oil-in-water emulsion. Oil rejection for the composite membranes ranges from $87.62 \%$ to $92.67 \%$ as against $83.4 \%$ of the pristine membrane. Result also shows that all composite membranes show higher water permeability and oil rejection as compared to the pristine membrane. Among all other composite membranes, membranes incorporated with $\mathrm{TiO}_{2}(\mathrm{Ti})$ show superiority in terms of water fluxes and anti-fouling properties. Overall, the results in this work indicated that the addition of $\mathrm{TiO}_{2}$ offer a better performance efficiency, making the nanoparticle a potential to mitigate fouling phenomenon in membrane-based separation processes.

\section{ACKNOWLEDGEMENTS}

The authors would like to acknowledge the financial support by Transdisciplinary Research Grant Scheme (TRGS), Ministry of Higher Education Malaysia (grant no: 203.PJKIMIA.67612001) and Universiti Sains Malaysia (USM) Research University (RUI) grant (grant no. 1001.PJKIMIA.8014063). One of the authors would like to express her thanks to USM Fellowship for financing her studies. The authors also would like to acknowledge T. A. Otitoju for presenting this research at the conference and carrying out editing of the article.

\section{REFERENCES}

1. Acero, J. L. et al. (2012). Coupling of adsorption, coagulation, and ultrafiltration processes for the removal of emerging contaminants in a secondary effluent. Chem. Eng. J., 210, 1-8.

2. Mosqueda-Jimenez, D. B., Narbaitz, R. M. \& Matsuura, T. (2004). Manufacturing conditions of surface-modified membranes: Effects on ultrafiltration performance. Sep. Purif. Technol., 37(1), 51-67, https://doi.org/10.1016/j.seppur.2003.07.003.

3. Rahimpour, A. et al. (2012). Novel functionalized carbon nanotubes for improving the surface properties and performance of polyethersulfone (PES) membrane. Desalin., 286, 99-107, https://doi.org/10.1016/j.desal.2011.10.039.

4. Zhao, C. et al. (2013) Modification of polyethersulfone membranes: A review of methods. Progr. Mater. Sci., 58(1), 76-150.

5. Luo, M.-L. et al. (2005). Hydrophilic modification of poly(ether sulfone) ultrafiltration membrane surface by self-assembly of $\mathrm{TiO} 2$ nanoparticles. Appl. Surf. Sci., 249(1), 76-84, https://doi.org/10.1016/j.apsusc.2004.11.054. 
6. Wu, G. et al. (2008). Preparation and characterization of $\mathrm{PES} / \mathrm{TiO}_{2}$ composite membranes. Appl. Surf. Sci., 254(21), 7080-7086.

7. Bolong, N. et al. (2009). Development and characterization of novel charged surface modification macromolecule to polyethersulfone hollow fiber membrane with polyvinylpyrrolidone and water. J. Membr. Sci., 331(1-2), 40-49, https://doi. org/10.1016/j.memsci.2009.01.008.

8. Wang, Y.-Q. et al. (2006). Generation of anti-biofouling ultrafiltration membrane surface by blending novel branched amphiphilic polymers with polyethersulfone. J. Membr. Sci., 286(1-2), 228-236, https://doi.org/10.1016/j.memsci.2006.09.040.

9. Otitoju, T. A., Ooi, B. S. \& Ahmad, A. L. (2019). Synthesis of 3-aminopropyltriethoxysilane-silica modified polyethersulfone hollow fiber membrane for oil-in-water emulsion separation. Polym., 136, 107-121, https://doi. org/10.1016/j.reactfunctpolym.2018.12.018.

10. Zinadini, S. et al. (2017). Preparation of antibiofouling polyethersulfone mixed matrix NF membrane using photocatalytic activity of $\mathrm{ZnO} / \mathrm{MWCNTs}$ nanocomposite. J. Membr. Sci., 529, 133-141, https://doi.org/10.1016/j. memsci.2017.01.047.

11. Basri, H., Ismail, A. F. \& Aziz, M. (2012). Microstructure and anti-adhesion properties of PES/TAP/Ag hybrid ultrafiltration membrane. Desalin., 287, 71-77, https://doi.org/10.1016/j.desal.2011.09.031.

12. Kango, S. et al. (2013). Surface modification of inorganic nanoparticles for development of organic-inorganic nanocomposites: A review. Progr. Polym. Sci., 38(8), 1232-1261.

13. Leo, C. P. et al. (2012). Polysulfone membranes blended with $\mathrm{ZnO}$ nanoparticles for reducing fouling by oleic acid. Sep. Purif. Technol., 89, 51-56, https://doi. org/10.1016/j.seppur.2012.01.002.

14. Vatanpour, V. et al. (2012). $\mathrm{TiO}_{2}$ embedded mixed matrix PES nanocomposite membranes: Influence of different sizes and types of nanoparticles on antifouling and performance. Desalin., 292, 19-29, https://doi.org/10.1016/j.desal.2012.02.006.

15. Ahmad, A. L. et al. (2017). Fouling evaluation of PES/ZnO mixed matrix hollow fiber membrane. Desalin., 403, 53-63, https://doi.org/10.1016/j.desal.2016.10.008.

16. Otitoju, T. A. et al. (2017). Polyethersulfone composite hollow-fiber membrane prepared by in-situ growth of silica with highly improved oily wastewater separation performance. J. Polym. Res., 24(8), 1-11, https://doi.org/10.1007/ s10965-017-1268-6.

17. Safarpour, M., Vatanpour, V. \& Khataee, A. (2016). Preparation and characterization of graphene oxide $/ \mathrm{TiO}_{2}$ blended PES nanofiltration membrane with improved antifouling and separation performance. Desalin., 393, 65-78, https://doi.org/10.1016/j.desal.2015.07.003.

18. Rajabi, H. et al. (2015). Nano-ZnO embedded mixed matrix polyethersulfone (PES) membrane: Influence of nanofiller shape on characterization and fouling resistance. Appl. Surf. Sci., 349, 66-77, https://doi.org/10.1016/j.apsusc.2015.04.214.

19. Ghandashtania, M. B. et al. (2015). A novel approach to fabricate high performance nano- $\mathrm{SiO}_{2}$ embedded PES membranes for microfiltration of oil-in-water emulsion. Appl. Surf. Sci., 349, 349-402, https://doi.org/10.1016/j.apsusc.2015.05.037. 
20. Balta, S. et al. (2012). A new outlook on membrane enhancement with nanoparticles: The alternative of ZnO. J. Membr. Sci., 389, 155-161.

21. Ng, L. Y., Leo, C. P. \& Mohammad, A. W. (2011). Optimizing the incorporation of silica nanoparticles in polysulfone/poly(vinyl alcohol) membranes with response surface methodology. Appl. Polym. Sci., 121(3), 1804-1814, https://doi. org/10.1002/app.33628.

22. Zhao, S. et al. (2015). Improving permeability and antifouling performance of polyethersulfone ultrafiltration membrane by incorporation of $\mathrm{ZnO}-\mathrm{DMF}$ dispersion containing nano-ZnO and polyvinylpyrrolidone. J. Membr. Sci., 478, 105-116, https://doi.org/10.1016/j.memsci.2014.12.050.

23. Guo, W., Ngo, H.-H. \& Li, J. (2012) A mini-review on membrane fouling. Biores. Technol., 122, 27-34. 